\title{
Yahudilerin Tapınak Siyaseti ve Semavi Mâbed*
}

\author{
Mustafa YİĞİTOĞLU \\ Yrd. Doç. Dr., Karabük Üniversitesi İlahiyat Fakültesi \\ Asst. Prof. Dr., Karabuk University, Theology Faculty \\ Orcid ID: 0000-0001-6308-1475 \\ mustafayigitoglu@karabuk.edu.tr
}

\section{Öz}

Yahudiliğin kurumsallaştığının bir göstergesi olan Mâbed; bu dinin müntesiplerince vazgeçilmez bir idea haline gelmiş̧ir. İlk dönemlerde Süleyman Mâbedi, bütün fonksiyonlarıyla Yahudiliğin merkezinde bir yer edinmişken, günümüzde ise bu yapının yokluğu Yahudilerde büyük etki yapmışır. Çünkü tapınaksız kalan Yahudiler, Mâbedsiz hayatın etkisini kaldıramamışlardır. Yahudiliğin devamlılı̆̆ı için alternatif çözüm yolları bulmaya yönelmişlerdir. Özellikle Semavi Mâbed fikri, yeryüzü Mâbedinin (Süleyman Mâbedi) yıkılması öncesi ve sonrasında Yahudi toplumunun varlığının devamını sağlayan olgulardan biri olarak ortaya çıkmıştır. Yahudilerin Tapınak Siyaseti ve Semavi Mâbed başlıklı bu çalışmada, Mâbed eksenindeki Yahudi düşüncesinin, bakış açısını tespit etmek gibi bir durum karşımıza çıkmaktadır. Burada ki maksat, Yahudi siyasi ve dini birçok alandaki geleceğe dair düşüncesinin ne üzerine temellendirildiğini genel bir çerçevede sunmaktadır. Hassaten Yahudi kutsal metinlerinde tapınağın tekrar inşasına yönelik müjdeli, umut verici, iyimser açılamalar bu ihtiyacın derecesini göstermektedir. Mâbedin ihyasına yönelik belirtilen her türlü beyanatlar Yahudileri her dönem ayakta tutmaya dair söylemler olmuştur. Zira Yahudiler için, Mâbedin dünyada ya da semada, bir şekilde var olması kaçınılmaz bir husustur.

Anahtar Kelimeler: Mâbed, Semavi Mâbed, Süleyman Mâbedi, Mescid-i Aksa, Yahudi, İslam.

\section{The Politics of the Jews of the Temple and the Heavenly Temple}

\begin{abstract}
Temple is an insurance of Jewish presence. Temple, a demonstration of Jewish institutionalization; this has become an indispensable idea for religious people. In the early days, the Solomon's temple had a place in the center of Judaism with all its functions, but today, the absence of this structure caused deep traumatism in the Jews. Because the Jews, who had no temple, could not remove the effect of the unfeeling life. A society that has been shattered from all directions has sought to find alternative solutions for the continuity of society. Indeed, the idea of Heavenly Temple emerged as one of the events leading to the existence of Jewish society before and after the destruction of the Earth's Temple (Solomon's Temple). In this work a situation emerges, such as determining the point of view of Jewish thought in the axis of the temple. The purpose here is to provide a general framework of what the Jewish political and religious opinion on the future is based on.
\end{abstract}

Keywords: Temple, Heavenly Temple, Solomon's Temple, Masjid al-Aqsa, Jews, Islam.

* Bu çalışma yazarın "Yahudilikte Semavî Mâbed Anlayışı” adlı doktora tezinden üretilmiştir. 


\section{Giriş}

Yahudi hayatının hemen hemen her safhasında merkezi konumda olan Mâbed hiç şüphesiz dini bakımdan da bu niteliğini muhafaza etmiştir. Kutsal Kitap'ta vaad edilen neslin devamı bu Mâbedin teşekkülü ile mümkün gözükmektedir. Mâbed bu halkın sigortası mahiyetinde olan bir özelliğe sahiptir. Geçmişten günümüze dünya üzerindeki Yahudilerin dini ve siyasi politikasını belirleyen bir husus olmuştur. O halde Mâbed tasavvurunu çok iyi izah etmek Yahudilerin geleceğini anlamaktır denilebilir. Bu nedenle incelemede ele alınan husus, aslında Yahudiliğin asırlar boyunca süregelen Mâbed çerçevesinde şekillenen algıları ile geleceğe dair düşünceleridir. Buradaki temel gaye, Yahudi düşüncesinin ne üzere temellendirildiğini genel hatları ile çizmek ve bu konuda bazı görüşleri açılamaktır. İlk olarak bu araştırmada Yahudilerce çokça önemsenen Kral Süleyman tarafından inşa ettirilen Süleyman Mâbedinin önemine yer verilmiştir. Müteakibinde Mâbedin önemi etrafında bunun yokluğu, yeniden imarı çalışmaları ve tasavvur edilen nihai devlet ve gökte mevcut mâbedin yeryüzüne nüzulü ele alınmıştır. Bu araştırma, Yahudilerin geleceği bina etmedeki düşüncelerini, çevresindeki uluslara ve dünya üzerindeki milletlere karşı sergilediği tutumları izah etme bakımından da hayli dikkate değerdir.

Kudüs, üç büyük din açısından kutsal kabul edilen beldedir. Ursalim ${ }^{1}$ olarak adlandırılan bu toprakların en eski meskunları Kenanlılardan sonra İsrailoğullarıdır. ${ }^{2}$ İsrâiloğulları yerleşik hayata geçmelerine ve Kral Süleyman tarafından tapınağın inşa edilmesine kadar göçebe bir yaşam sürdürmüşlerdir. Bundan dolayı ibadet edebilmeleri maksadıyla konaklama noktalarına ve önem atfettikleri; Şekem, Beytel, Mamre ve Berşeba gibi belirli yerlere çeşitli sunaklar yapmışlardır. ${ }^{3}$ Yahudilerin ibadet yeri bakımından en önemli ilk değişikliği Mûsâ dönemi ile birlikte görülmektedir. Bu dönemde ibadetlerini icra edebilmek gayesi ile mâbed olarak 'toplanma çadırı' Ohel Moed, Makdis', Mişkan ${ }^{5}$ oluşturulduğu bilinmektedir. Yahudilerin tapınak arayışları Kral Süleyman'ın mâbedi'ni inşasına kadar devam etmiştir.

${ }^{1}$ Hamevi, Ebu Abdullah Şehabeddin Yakut b. Abdullah Yakut 626/1229), Mu'cemü'I-Buldan I, 3, tahkik: Ferid Abdü'l-Aziz el-Cündi, Daru'l-Kütübi'l-İlmiyye, t.y, Beyrut.

${ }^{2}$ Eldar Hasanoğlu, “Tanah'a Göre Kudüs'ün Kutsallaşma Süreci”, Uludă̆ Üniversitesi İlahiyat Fakültesi Dergisi 24/2, (2015): 127.

${ }^{3}$ Ahmet Güç, Dinlerde Mabet ve İbadet, (2. Basım, İstanbul: Ensar Neşriyat, 2005), s. 102.

${ }^{4}$ Ahmet Güç, "Mâbed", Türkiye Diyanet Vakfı İslâm Ansiklopedisi (DİA), c.XXVII, s. 276-280.

${ }^{5}$ Mişkan (Mishkan-Tabernacle) taşınabilir çadır mâbed veya tapınak gibi anlamlara da gelir. 
Yahudiler açısından Mâbed; dini, hukuki, sosyal ve birçok açıdan çeşitli özelliğe sahiptir ve Kral Süleyman'a tanrı tarafından bizzat inşa ettirilmiştir. ${ }^{6}$ Buradaki en büyük payın tanrıya ait olduğu ve burasının tanrının eliyle tasarlandığ1 ifade edilmektedir. 7 Zira bu tapınak, bu dinin müntesiplerinin inancı gereği, tanrı ile milleti arasındaki bağın kurulduğu tek yerdir. İçerisinde kutsal kabul edilen araç-gereçler bulunmaktadır. ${ }^{8}$ Burası vasıtası ile Yahudiler çeşitli takdimelerini ve dini ritüellerini ancak Mâbedde icra edebilmektedir. ${ }^{9}$ Doğal olarak bu mekân; Yahudilerce yapılabilecek bütün ibadetlerin merkezi bir kurumu olmuştur. Bundan dolayı da ebedi mâbed ${ }^{10}$ olarak nitelendirilen Kral Süleyman Mâbedi, tanrının ebedi sembolü haline gelmiştir.11 Tanrı'nın ikamet ettiği, Kutsal Kitapt'a sonsuz ev olarak nitelendirilen bu yer, vuku bulan çeşitli saldırılar neticesinde tahrip edilmiş ve nihayetinde yıkılmıştır. Bu durum Yahudi hayatında telafisi mümkün olamayacak derecede sıkıntıların oluşmasına yol açmıştır. Zira Yahudilere göre bütün yakarmalar, dualar burası ile mümkündür. ${ }^{12}$ Aksi halde Mâbedin olmaması halk ile tanrı arasında iletişimin kopması demekti. Bu sebeple Yahudiler tanrı ile bir bağ kuramadıklarından yakınmışlar, bazı Yahudiler bundan dolayı din değiştirmek durumunda kalmışlardır. ${ }^{13}$ Yahudiler arasından irtidat etmeyip dini inanışını devam ettirenler ise Mâbedin bir gün yeniden inşa edileceği düşüncesine inandırılmışlardır. ${ }^{14}$

\section{Kral Süleyman Dönemi ve Mâbed'in İnşası}

Yahudi Kutsal Kitab'ında yer aldığı şekliyle mâbed, Davud'un oğlu Süleyman tarafından bizzat tanrının isteği neticesinde yaptırılmıştır. ${ }^{15}$ Yapımı için Sur Kralı Hiram'dan destek alan Kral Süleyman halkının Mısır'dan çıkışından dört yüz seksen yıl sonra, krallığının dördüncü yılında tapınağın yapımına başlamış, krallığının on birinci yılının sekizinci ayında ise bütün ayrıntılarıyla yedi yıl içerisinde tamamlamıştır. ${ }^{16}$

\footnotetext{
${ }^{6}$ I. Tarihler, 28/6.

${ }^{7}$ Alexander Kristianpoller, Temple in Talmud in Midrash, (Isaac Landman, Newyork: 1948), s. 196.

${ }^{8}$ Bkz.I. Krallar, 8/ 2-8.

${ }^{9}$ Geniş bilgi için bkz. Mustafa Yiğitoğlu, Dinlerde Dua, Sunu ve Sunaklar, İstanbul: Beka Yay, 2015.

${ }^{10}$ Hezekiel, 43/7.

${ }_{11}$ Max, Margolis, Alexander Marx, A History of the Jewish People, (Cleveland and Newyork: Meridian Books, 1962), s. 65.

12 I. Krallar, 8/ 44-48.

${ }^{13}$ Shaye J. D Cohen, "Roman Domination, The Jewish Revolt and the Destruction of the Second Temple", Ancient Israel, Hershel Shanks (drl), Washington: Biblical Archaeology Society, 1999.

14 Victor H. Matthews, Manners and Customs in the Bible, 7. Bask1, Massachusets: Hendrickson Publishers, 1991. s. 180.

${ }^{15}$ I. Krallar, 5/1-4.

${ }^{16}$ I. Krallar, 6/15-38. Mâbed ile ilgili benzer bilgiler için bkz. Çıkış, 26/33-34; 30/1-3; 25/18-20.
}

Türkiye İlahiyat Araştırmaları Dergisi Turkey Journal of Theological Studies [Tiad: 2602-3067]
Cilt / Vol : 1, Sayı/Issue: 1 , 2017 
Kral Süleyman'ın ölümü sonrası devlet, İsrail ve Yahuda adıyla ikiye bölünmüş ve Kuzeyde bulunan İsrail Devleti Asurlular tarafından yıkılmıştır. Müteakibinde yaklaşık 150 yıl sonra Nabukaddnezzar'ın kral olmasıyla Babilliler güneyde yer alan Kral Yehoyakim liderliğindeki ${ }^{17}$ Yahuda Krallığına (M.Ö. 586-7) son vermiştir. ${ }^{18}$ Neticesi sürgün ve tapınağın yıkılması olan büyük bir felaket yaşanmıştır. Tapınağın içerisinde yer alan kutsal eşyaların Babil'e götürüldügü bilinmektedir. Kutsal Kitabın içerisinde olan ahit sandığının ise Babil'e götürüldüğü, mâbedle birlikte parçalandığı veya Maneşşa tarafından alındığ 1 rivayet edilmektedir. ${ }^{19}$

\section{Sürgünden Dönüş ve Mâbed'in Tekrar Yapımı}

Babil'deki sürgün müddetince Yahudiler cebir yoluyla ayrıldıkları bölgeye geri dönme arzusunu muhafaza ederek bu umudu sürekli canlı tutmuşlardır. $\mathrm{Bu}$ durum, kendilerini her şarta uyum sağlamasına ve ulusal bir hayatın yeniden doğmasına zemin hazırlamıştır. ${ }^{20}$ Kral Nabukadnezzar'ın M.Ö. 561'de vefatı neticesinde Bâbil Devleti hızla çöküşe geçmiş²1 ve Persler tarafından ortadan kaldırılmıştır. ${ }^{22}$ Böylelikle Filistin toprakları, Pers İmparatorluğu'na geçmiştir. $^{23}$ Yahudiler, Kral Koreş'in ${ }^{24} 539$ yılında Bâbil'i yok etmesinden, Kudüs'e dönmelerine ve mâbedi tekrar ihya etmelerine müsaade edene kadar uzun bir süre Pers idaresinde hayatlarını idame ettirmişlerdir. ${ }^{25}$ Kral Koreş'in izni ile birlikte Kudüs'e geri dönen Yahudiler mâbedi tekrardan imar etmek istemişlerdir. Kutsal Kitap'ta II. Mâbed'in temelinin kimler tarafından ve ne zaman atıldığına dair net bir bilgi de yoktur. Şeşbassar, Yosadak oğlu Yeşu ve Zerubabel isimleri farklı metinlerde geçmektedir. ${ }^{26}$ Herod döneminde Mâbedin eskisinden gösterişsiz olması nedeniyle yeni plan ve proje

\footnotetext{
17 II. Krallar, 24/11-14.

${ }_{18}$ Ronald H. Sack. Images of Nebuchadnezzar, London: Susquehenna University Press, 1991, s.48

19 Peter R. Ackroyd, Exile and Restoration/A Study of Hebrew Thought of the Sixth Century B.C., Philadelphia: TheWestminster Press, 1975, s. 25

${ }^{20}$ Grintz Yehoshua "Temple, First Temple”, EJd, Celil Roth (ed.), Jerusâlem: Keter Publishing House,1978, s. 945

${ }^{21}$ Miller J. Maxwell, John Haralsın Hayes, A History of Ancient Israel and Judah, Philadelphia: The Westminster Press, 1986, s. 439

${ }^{22}$ Kenneth G. Hoglund, Achamenid Imperial Administration in Syria-Palestine and the Missions of Ezra and Nehemiah, Atlanta: Scholars Press, 1992, s. 437

${ }^{23}$ Lawrence H. Schiffman, From Text to Tradition, a History of Judaism in Scond Temple and Rabbnic Times, USA: Ktav Publishing House, 1991, s. 33.

${ }^{24}$ Kral Koreş, Yahudi Kutsal Kitabı'nda övülerek 'Tanrı'nın çobanı, her istediğini yerine getiren, Kudüs ve tapınağının temelini atan' kişi olarak görülmüştür. Yeşeya, 44/28.

${ }^{25}$ Miller J. Maxwell, John Haralsin Hayes, s. 437.

${ }^{26}$ Ezra, 5/16; Ezra, 3/2 ve 6; Zekeriya, 4/8-10.
}

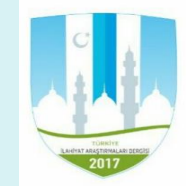

Türkiye İlahiyat Araştırmaları Dergisi 
kapsamında Kudüs ve Mâbed yeniden imar edilmiştir. ${ }^{27}$ Bu durum M.S. 70 yılında Romalıların Mâbedi yıkmasına dek sürmüştür.

\section{Mâbed'in Yıkılışı ve Mâbedsiz Dönem}

Roma'nın Yahudiler üzerine sürdürdüğü baskı politikası ile Zeolotların ${ }^{28}$ buna karşı takındığı tavır Yahudiler ile Romalılar arasındaki ilişkileri tamamen koparmıştır. Müeakibinde Yahudi isyanının başlaması ile Mâbed büyük oranda yıkılmış ve Yahudilerin geleceği ciddi bir şekilde tehlikeye girmiştir. ${ }^{29}$ M.S. 132 senesinde ise Bar Kohba'nın öncülüğünde Romalılara karşı tekrar ayaklanılmıştır. Nihayetinde Romalılarca Kral Süleyman tarafından inşa edilen mâbed tamamen yıkılmıştır. ${ }^{30}$ İlerleyen dönemlerde yıkılan şehir ve Mâbed yerine yine Romalılar tarafından M.S. 135'te bir putperest şehri ile Aelia Capitolina ve Jüpiter Capitolina'ya ithafen de tapınaklar yapılmıştır. ${ }^{31}$

Önceki pasajlarda Yahudilerin Mâbedin yokluğunda kendileri açısından olumsuz bir etki oluşturduğunu zikretmiştik. Mâbedin olmayışında ciddi sorunlar yaşayan Yahudilere teskin eden ve onlara telkin veren Kutsal Kitap metinleri çokça önemlidir. Zira buradaki ifadelerde Yahudilerin ümidini diri tutan söylemler ile vaadler, Yahudilerin benliklerini korumalarında ve alternatif geliştirmelerinde hayli kayda değerdir. Zekeriya'nın Tanrı'nın meleklerini görüp onlar ile münasebette bulunmass ${ }^{32}$ gibi açıklamalar tanrı ile herhangi bir irtibatın kopmadığına dair bilgilerdir ve umutsuzluğu giderici beyanatlardır. Yine aynı metinlerde Tanrı'nın Yahudilere hiddetlendiğini, fakat sonrasında muhakkak tapınağını tekrar kuracağı ifade edilmektedir. ${ }^{33}$ Böylelikle sıkıntı içerisindeki halkı ayakta tutabilmeyi amaçlamaktadır.

Özellikle, Hezekiel'de zikredilen Yeni tapınakla ilgili vizyon, Yahudi düşüncesinde yer alan kral Mâbedden kral devlete geçişin bir delili niteliğindedir. ${ }^{34}$ Hezekiel'de söz konusu bu metinlerde Kudüs'ün işgalinden on üç sene sonra, Tanrı'nın elinin onu tutarak İsrail topraklarına götürmesi, yüksekçe bir dağın tepesine bırakması ve orada gördüğü kente benzer yapılar

${ }_{27}$ Peter Richardson, Herod: King of the Jews and Friend of the Romans, Columbia: University of South Carolina Press, 1996, s. 245.

${ }^{28}$ Bir Yahudi mezhebi. Geniş bilgi için bkz. A. Agus, "Judaism", Historical Atlas of the Religions of the World, (Newyork: Macmillan Publishing Co. 1974), s. 147-148.

29 S. A. Nigosian, World Religions, (Edwarld Arnold (drl.), London, 1975), s. 39.

30 Michael Avi Yonah, "Temple, Second Teple, From the Roman Conquest until the Destruction", EJd, (Celil Roth (ed.), Jarusâlem: Keter Publishing House Jerusâlem Ltd 1978), s. 960.

${ }^{31}$ H. D. M. Spence-Jones, The Early Christians in Rome, (NewYork: John Lane Comp. 1911), s. 77. Ayrıca bkz. Mustafa Yiğitoğlu, “İsra ve Miraç'ta Süleyman Mâbedi ve Mescid-i Aksa'nın Varlığ1 Meselesi", Insan ve Toplum Bilimleri Araştırmaları Dergisi 7/1 (2017): 641-651.

32 Zekeriya, 1/9-13

33 Zekeriya, $1 / 16$.

${ }^{34}$ Mustafa Yiğitoğlu, "Yahudi ideası: Kral Mâbedinden Kral Devlete", Turkish Studies 7/2 (2012) s. 1211.

Türkiye İlahiyat Araştırmaları Dergisi Turkey Journal of Theological Studies [Tiad: 2602-3067]
Cilt / Vol : 1, Sayı/Issue: 1 , 2017 
ile tunca benzeyen bir adamın ona 'Sen bunun için buraya getirildin. Göreceğin her şeyi İsrail halkına söyle’35 diyalogu geçmektedir. Burada zikrolunan ve Hezekiel'e gösterilen vizyon, son günlerde yeryüzüne indirilecek bir şehir ile ilgilidir. Kutsal Kitap'ta bahsedilen, Hezekiel'in vizyonuna benzeyen bir vizyon da Levi'nin Ahdi'nde yer almaktadır. Levi'nin Ahdi (M.Ö. I. yy. ile M.S. I. yy arası) Hezekiel'in 40/1-4 'teki baplarının yansıması gibidir. Metinlerde Tanrı'nın Levi'yi semâya davet etmesi, Tanrı'nın davetine onun icabet etmesi ve orada Levi'nin görmüş olduğu olağanüstü bir vizyon söz konusudur. ${ }^{36}$

Yahudi düşüncesinde, Tanrı dünyayı ve dünya üzerindeki her şeyi var eden kabul edildiği için doğal olarak semâdaki her şey de tanrı tarafından yaratılmıştır. Bu nedenle yeryüzü, yeryüzü şehrinin bir yansıması 'Semâvî Kudüs' ve Kudüs'teki mâbedin bir yansıması olarak da semâvî mâbed, onun tarafından yaratılmıştır. Tanrı'nın yeryüzündeki mâbede sevgisinden dolayı O, onun bir benzerini semâda oluşturmuştur. Kutsal Kitap'ta 'ben şehre girmeyeceğim ${ }^{\prime 37}$ ifadesiyle, Tanrı'nın yeryüzü inşa edilinceye kadar semâvî Kudüs'e girmeyeceği anlaşılmaktadır. Tanrı'nın, 'insanlar bulundukları yerden alındığında Kudüs'te benim için ne vardır?'38 sözü Kudüs'e girmeyeceğini desteklemektedir.

Kutsal Kitap'ta ilgili metinler incelendiğinde, Tanrı'nın semâda bir mekân olarak Kudüs Şehrini yarattığı sonucu çıkmaktadır. Mezmurlar'da geçen 'işte budur Rabb'in kapısı! Doğrular girebilir oradan'39 ifadesi de Tanrı'nın yarattığı Semâvî Kudüs'ü teyit etmektedir. Kabala'nın prensibine göre dünya semânın bir yansıması olarak var edilmiştir. ${ }^{40}$ Talmud'da söz konusu açıklamalardan, Kudüs'ün her iki yerde var olduğu ve yeryüzü mâbedi yıkılmasına rağmen semâvî mâbedin varlığını devam ettirdiği anlaşılmaktadır. ${ }^{41}$

\footnotetext{
${ }^{35}$ Hezekiel, 40/1-4. Ayrıca Tanrı'nın Kudüs'üu tekrar seçmesi ve Mâbedini yerleştirmesi ile ilgili bilgiler için bkz. “Onun için Rab, 'Kudüs'e sevecenlikle döneceğim' diyor, 'Tapınağım orada yeniden kurulacak ve Kudüs üzerine ölçü ipi çekilecek!' Böyle diyor her şeye egemen Rab. şunu da duyur: Her şeye egemen Rab, 'Kentlerim yine bollukla dolup taşacak' diyor, 'Ben Rab, Siyon'u yine avutacağım, Kudüs "ü yine seçeceğim." Zekeriya, 1/16-17.

${ }^{36}$ R. G. Hamerton-Kelly "The Temple and the Origins of the Jewish Apocalyptic", Vetus Testamentum 20/1 (1970), s.6

${ }^{37}$ Hoşea, 11/9.

${ }^{38}$ Noward Schwartz, Tree of Souls, The Mythology of Judism, Caren Loebel-Fried (drl.), (USA: Oxford University Press, 2004), s. 414.

${ }^{39}$ Mezmurlar, 118/20.

${ }^{40} \mathrm{Bkz}$. Zohar, 2/50b-51a.

41 Talmud, Ta'anit 5a.
} 
Yeşeya, 2/2' de Mesih döneminde, mâbedin dağlar üzerine inşa edileceği iddia edilmiş; hatta mâbedin yapılacağı dağların sayısı ve isimleri de zikredilmiştir. Gerçi belirtilen görüşlerdeki dağların sayısı ve isimlerinde ise farklılık mevcuttur.

Bazı ifadelerde, Semâvî Kudüs'ün tamamı üç ya da dört dağa dayalı olarak yeryüzüne, bazılarında ise, mâbed sadece dağların üzerine inecektir. Pesikta de Rav Kahana, “Tanrı üç dağ getirecek, Sina, Tabor ve Karmel bunların hepsinin üzerine mâbed inşa edilecektir." 42 Gelecekte, Tanrı'nın bütünüyle semâvî Kudüs'ü yeryüzüne indireceğini düşünenler ise; iki kutsal metne ${ }^{43}$ dayanarak son günlerde bu şehrin dört dağ üzerine ${ }^{44}$ indirileceğini iddia etmektedir.

Mesih çağının önemli delillerinden biri Kudüs'te mâbedin tekrar kurulması olacaktır. Bu hadisede mâbedin yeniden inşası problemi, Semâvî Kudüs'ün varlığı, Semâvî Mâbed dahil, yeryüzüne inişi ve üç ya da dört dağa konuşlanması ile çözülecektir. ${ }^{45}$ Hezekiel bölümünün sonlarındaki gerçekleşen vizyonda gelecekteki şehrin ve mâbedin tanımının yapılması, Semâvî Kudüs'ün ve semâvî mâbedin varlığını desteklemektedir. ${ }^{46}$

\section{Sonuç}

Yahudiler açısından çokça öneme sahip olan Mâbed, varlığında ibadetler ve birçok ritüeller açısından bir merkez olmuştur. Kral Süleyman tarafından inşa edilen Mâbedin yokluğu ise, Yahudi toplumu açısından ciddi problemler doğurmuştur. Fakat halk ona olan ihtiyacı ve ilgiyi azaltmamış bilakis ziyadesiyle artırmışlardır. Kutsal metinler de Mâbedin gereksinimi anlatılarak geleceğe dair umutlar verilmiştir. Mâbedin yeniden inşasıyla ilgili bu ifadeler ve vaadler halkı diri tutmaya, yeknesak bir toplum olmaya sevk etmiştir. Lakin kutsal metinlerde serdedilen Mâbedin yeniden yapımıyla ilgili sözlerin gerçekleşmeyişi Yahudi halkı üzerinde hayal kırıklığına sebep olmuştur. Buna rağmen her zaman ümitvar olan Yahudier Mâbedin yapılması için geçmişten günümüze kadar çokça çaba sarf etmeye devam etmektedir. Hadd-i zâtında Yahudiler, 1948'de bağımsızlığın ilanı sonrası, kendi varlıklarının teminini sağlamak maksadıyla her türlü etkene karşı çözüm bulmak durumunda kalarak, günden güne Filistin topraklarında iskân politikasını genişletip nüfusunu artırmayı sürdürmektedir. Buna ilaveten gizliden Mâbed siyaseti güderek Süleyman Mâbedi'nin olduğu alanda kazı faaliyetlerini devam

42 Pesikta de Rav Kahana, 21/4.

${ }^{43}$ Yeşeya, 2/2; 52/7

${ }^{44}$ Kutsal dört dağ, Sina, Tabor, Karmel ve Hermon. Bazı rivayetlerde üç dağın zirvesine indirilecektir. Hermon Dağ istisna tutulur.

${ }^{45}$ Schwartz, s. 418.

${ }^{46}$ Hezekiel, 40/1-2. Semavi Mâbedin varlığına dair geniş bilgi için bkz. Mustafa Yiğitoğlu, Yahudilikte Tanrı'nın Yeri: Semavi Mâbed, İstanbul: Bayem Ajans, 2011. 
ettirmektedir. Bu politika gereği fiziki Mâbedin yeniden inşasını hayata geçirmek istemektedirler. Olası fiziki Mâbedin yapılamayışında ise alternatif bir anlayış geliştirilerek Yahudilere daima bir ümit verilmektedir. Bu, fiziki Mâbedin olmayışında liturjiye uyum sağlamış olan Mâbed, yani Yahudilerin ihtiyaç duyduğu geçici çözüm arayışı sinagoglardır. Fakat ana gayeyi teşkil eden kutsal metinlerde de belirtilen Tanrı ya da Mesih tarafından gerçekleştirilecek olan alternatif Mâbed söz konusudur. Böylelikle kutsal kitapta tanrı tarafından vaad edilen toprakların ve burada yer alacak tapınağın gerçekleşmesi ile Yahudi düşüncesindeki yeni bir döneme de kapı aralanmış olacaktır. 


\section{Kaynakça}

Ackroyd, Peter R., Exile and Restoration/A Study of Hebrew Thought of the Sixth Century B.C., Philadelphia: TheWestminster Press, 1975.

Agus, A., "Judaism", Historical Atlas of the Religions of the World, Newyork: Macmillan Publishing Co. 1974, s. 147-148.

Avi Yonah, Michael, “Temple, Second Teple, From the Roman Conquest until the Destruction", EJd, (Celil Roth (ed.), Jarusâlem: Keter Publishing House Jerusâlem Ltd 1978.

Cohen, Shaye J. D, "Roman Domination, The Jewish Revolt and the Destruction of the Second Temple", Ancient Israel, Hershel Shanks (drl), Washington: Biblical Archaeology Society, 1999.

Grintz Yehoshua, "Temple, First Temple", EJd, Celil Roth (ed.), Jerusâlem: Keter Publishing House,1978.

Güç, Ahmet, "Mâbed", Türkiye Diyanet Vakfı İslâm Ansiklopedisi (DİA), c. XXVII, s. 276-280.

Güç, Ahmet, Dinlerde Mabet ve İbadet, 2. Basım, İstanbul: Ensar Neşriyat, 2005.

Hamerton-Kelly, R. G., "The Temple and the Origins of the Jewish Apocalyptic", Vetus Testamentum 20/1 (1970), s. 1-15.

Hamevi, Ebu Abdullah Şehabeddin Yakut b. Abdullah Yakut 626/1229), Mu'cemü'I-Buldan I, 3, tahkik: Ferid Abdü'l-Aziz el-Cündi, Daru'l-Kütübi'lİlmiyye, t.y, Beyrut.

Hasanoğlu, Eldar, “Tanah'a Göre Kudüs'ün Kutsallaşma Süreci”, Uludă̆g Üniversitesi İlahiyat Fakültesi Dergisi 24/2, (2015): 125-148.

Hoglund, Kenneth G., Achamenid Imperial Administration in Syria-Palestine and the Missions of Ezra and Nehemiah, Atlanta: Scholars Press, 1992.

Kristianpoller, Alexander, Temple in Talmud in Midrash, Isaac Landman, Newyork: 1948.

Margolis, Max, Alexander Marx, A History of the Jewish People, Cleveland and Newyork: Meridian Books, 1962.

Matthews, Victor H., Manners and Customs in the Bible, 7. Bask1, Massachusets: Hendrickson Publishers, 1991.

Maxwell, Miller J., Hayes, John Haralsın, A History of Ancient Israel and Judah, Philadelphia: The Westminster Press, 1986.

Nigosian, S. A., World Religions, Edwarld Arnold (drl.), London, 1975.

Türkiye İlahiyat Araştırmaları Dergisi

Turkey Journal of Theological Studies

[Tiad: 2602-3067]
Cilt / Vol : 1,

Sayı/Issue: 1 ,

2017 
Richardson, Peter, Herod: King of the Jews and Friend of the Romans, Columbia: University of South Carolina Press, 1996.

Sack, Ronald H., Images of Nebuchadnezzar, London: Susquehenna University Press, 1991.

Schiffman, Lawrence H., From Text to Tradition, a History of Judaism in Scond Temple and Rabbnic Times, USA: Ktav Publishing House, 1991, s. 33.

Schwartz, Noward, Tree of Souls, The Mythology of Judism, Caren Loebel-Fried (drl.), USA: Oxford University Press, 2004.

Spence-Jones, H. D. M., The Early Christians in Rome, NewYork: John Lane Comp. 1911.

Yiğitoğlu, Mustafa, “İsra ve Miraç'ta Süleyman Mâbedi ve Mescid-i Aksa'nın Varlığı Meselesi”, İnsan ve Toplum Bilimleri Araştırmaları Dergisi 7/1 (2017): 641651.

Yiğitoğlu, Mustafa, "Yahudi ideası: Kral Mâbedinden Kral Devlete", Turkish Studies 7/2 (2012) s. 1211.

Yiğitoğlu, Mustafa, Dinlerde Dua, Sunu ve Sunaklar, İstanbul: Beka Yay, 2015.

Yiğitoğlu, Mustafa, Yahudilikte Tanrı'nın Yeri: Semavi Mâbed, İstanbul: Bayem Ajans, 2011. 